\title{
Meeting In-Between: Moving beyond the buzz, bottlenecks, and bubble to collaboratively develop digitization tooling
}

\author{
Matthew Yoder $\ddagger$ \\ ‡ University of Illinois, Champaign, United States of America
}

Corresponding author: Matthew Yoder (diapriid@gmail.com)

Received: 02 Oct 2020 | Published: 09 Oct 2020

Citation: Yoder M (2020) Meeting In-Between: Moving beyond the buzz, bottlenecks, and bubble to collaboratively develop digitization tooling. Biodiversity Information Science and Standards 4: e59265. https://doi.org/10.3897/biss.4.59265

\begin{abstract}
Specimen digitization software and tooling is moving well past its third decade of development, yet in many ways new tools have yet to leapfrog or overcome the initial innovation realized years ago. Here I argue that a biodiversity informatics bubble has emerged, creating demands of digitization tools that are not always in line with the requirements of physical specimen curators (or others doing actual science). Pressuring tools to keep up with concepts that have emerged from this bubble, for example Life Science Identifiers (LSIDs), and its parallels in the tech industry, for example microservices, has detracted from advancements that could be made with respect to dayto-day workflows and practices of the curators themselves. These advances in turn might provide a more enjoyable, intuitive, and ultimately sustainable foundation perhaps more immune to inevitable bubble bursts, hype-based derailments, and changes in scientific goals. How then should development proceed? We can observe that existing digitization software largely fits into two sides of the spectrum: commercial monoliths like EMu and "home-grown" efforts, e.g. Specify, Arctos, and Symbiota. I argue the latter are much more in-tune with user needs, because they were first built by the users themselves. Our approach, therefore, should be to go back to the well, the curator, the digitizer, the student hourly, and the person who has to fulfill requests of those using the physical collection itself, and seek their needs, and understand their experiences. With this understanding in
\end{abstract}


place, i.e., a solid user-interface/experience foundation, we can build out tooling (and standards) that developers will want to utilize in their own software. These arguments and ideas are contextualized against TaxonWorks (http://taxonworks.org) and the experiences of the five collections now using it to digitize collections to illustrate their shortcomings and potentialities.

\section{Keywords}

digitization, software, biodiversity informatics

\section{Presenting author}

Matthew Yoder

\section{Presented at}

TDWG 2020

\section{Hosting institution}

Species File Group, Illinois Natural History Survey, University of Illinois

\section{Conflicts of interest}

None. 